\title{
Bond cleavage reactions in the tripeptide trialanine upon free electron capture
}

\author{
Benjamin Puschnigg, Stefan E. Huber, Paul Scheier, Michael Probst and Stephan Denifl* \\ Institut für Ionenphysik und Angewandte Physik and Center of Molecular Biosciences Innsbruck, \\ Universität Innsbruck, Technikerstr. 25, A-6020 Innsbruck, Austria
}

\begin{abstract}
In the present study we performed dissociative electron attachment (DEA) measurements with the tripeptide trialanine, $\mathrm{C}_{9} \mathrm{H}_{17} \mathrm{~N}_{3} \mathrm{O}_{4}$, utilizing a crossed electronmolecular beam experiment with high electron energy resolution $(\sim 100 \mathrm{meV})$. Anion efficiency yields as a function of the incident electron energy are obtained for the most abundant anions up to electron energies of $\sim 4 \mathrm{eV}$. Quantum chemical calculations are performed to determine the thermochemical thresholds for the anions observed in the measurements. There is no evidence of a molecular anion with lifetime of mass spectrometric timescales. The dehydrogenated closed shell anion $(\mathrm{M}-\mathrm{H})^{-}$is one of the fragment anions observed for which the calculations show that H-loss is energetically possible from carboxyl as well as amide groups. In contrast to the dipeptide dialanine and monomer alanine the cleavage of the $\mathrm{N}-\mathrm{C}_{\alpha}$ bond in the peptide chain is already possible by attachment of electrons at $\sim 0 \mathrm{eV}$.
\end{abstract}

*Corresponding author. Email address: Stephan.Denifl@uibk.ac.at (Stephan Denifl)

Running title: Free electron capture by trialanine 


\section{Introduction}

The degradation of biological matter due to the interaction with ionizing radiation includes an early physical stage where a large amount of secondary species is formed [1]. Among these species are secondary electrons, formed abundantly by direct ionization processes with removal of valence or inner shell electron(s) as well as indirect ionization processes like interatomic Coulombic decay where inner valence shell ionization leads to subsequent ionization of a neighbouring molecule due to transfer of excitation energy by means of a virtual photon [2]. The energy distribution of secondary electrons yields peaks typically below $100 \mathrm{eV}$ with an abundant amount below sub-ionization energies [3]. At such low energies dissociative electron attachment may lead to an efficient subsequent degradation of biological compounds by entering the chemical stage of radiation damage [4]. Therefore an extended amount of experimental and theoretical studies on electron induced damage in biomolecules have been carried out over the last recent years. These studies have been initiated by a pioneering investigation of the damage of a plasmid DNA induced by low energy electrons [4]. The damaging effect was ascribed to transient negative ion formation which triggered dissociation processes in the molecular DNA network which could lead to strand breaks.

In addition to the study of DNA and related molecules, attention has been also paid to the degradation of amino acids and peptides by low energy electrons either. Being the subunits of proteins which form the spool for packing DNA as histone, their role in radiation damage is still not fully understood yet. Some of the protein components intercalate within the DNA grooves, i.e. they may directly interact with the DNA building blocks. As a consequence, fragmentation of proteins may result in the formation of reactive species in the vicinity of DNA which may induce structural (irreversible) damage. In contrast, it was also suggested that the presence of proteins could buffer more severe damage of DNA. Peptides are characterized by $\mathrm{OC}-\mathrm{NH}$ bonds formed from adjacent amino acids. Investigations with peptides may provide information relevant for the decomposition of proteins due to ionizing radiation and subsequently formed low-energy electrons. In contrast to single amino acid molecules [5-14] only few electron attachment studies on neutral peptides [15-22] have been carried out so far, where, to the best of our knowledge, resonant ion yields as the function of the electron energy were only determined for few dipeptides. Since neutral targets are used in the present and earlier [15-22] studies, we note in this context that the process is different from electron capture dissociation (ECD) of deprotonated peptides or multiply charged peptide cations generated by electrospray ionization. ECD became popular as a technique for 
ion activation in tandem mass spectrometry, where, for example, dianions were recently detected that had been rarely observed before [23].

In electron attachment to neutral amino acids the dehydrogenated closed shell anion is formed as the most abundant anion at subexcitation energies. The site of hydrogen loss was identified to be the carboxyl group shown in experimental as well as theoretical studies. The captured electron occupied the repulsive $\sigma^{*}(\mathrm{OH})$ orbital, where only the lower energy tail (up to $\sim 2 \mathrm{eV})$ of the broad resonance $(5.8 \mathrm{eV}$ broad and centred at $5.3 \mathrm{eV})$ appears in the DEA cross section due to effective autodetachment including vibrational excitation of the remaining neutral molecule at higher energies $[9,24]$. A second resonance was formed at $\sim 5.5$ $\mathrm{eV}$, where other sites of hydrogen loss are accessible by this resonance.

Recently we carried out a detailed low-energy electron attachment study to the dipeptide dialanine $[15,16]$. This molecule decomposes strongly upon capture of a low-energy electron which leads to a number of fragment anions and corresponding neutrals. The formation of the dehydrogenated parent anion, $(\mathrm{M}-\mathrm{H})^{-}$, turned out to be a particularly intense reaction channel and highly site selective as a function of the initial electron energy. Resonant peaks in the (M$\mathrm{H})^{-}$yield were assigned to hydrogen loss from both the amide and carboxyl groups [16]. In the present work we investigate the negative ion formation for the tripeptide trialanine $\left(\mathrm{C}_{9} \mathrm{H}_{17} \mathrm{~N}_{3} \mathrm{O}_{4}\right)$. Low energy DEA in the electron energy range from $\sim 0$ up to $4 \mathrm{eV}$ is investigated by recording the ion efficiency curves of fragment anions as a function of the initial electron energy. The measured resonances are compared with the thermochemical thresholds for the dissociation channels derived by quantum chemical calculations.

\section{Experimental Setup}

Electron attachment to trialanine was investigated by means of a crossed electronmolecular beam set-up which has been described in detail elsewhere [25]. Briefly, an electron beam with a full width at half maximum (FWHM) of about $100 \mathrm{meV}$ was formed in a hemispherical electron monochromator with typical currents of $\sim 5 \mathrm{nA}$. The trialanine sample was purchased from Sigma Aldrich, Vienna, Austria, and had a stated purity of $>98 \%$. The sample is solid at room temperature and had to be heated in an oven installed in the monochromator chamber. An effusive molecular beam emerged through a capillary attached to the heated oven which was operated at a temperature of around $420 \mathrm{~K}$. The negative ions formed in the interaction region were extracted by a weak electric field and were mass analyzed in a quadrupole mass filter. We note that the mass analyzer has a considerable 
discrimination of heavy anionic species and thus the measured relative abundance of the dehydrogenated parent anion will not reflect its true abundance. The mass analysed anions were finally detected by a channeltron type secondary electron multiplier operated in single pulse counting mode. The yields of mass-selected anions were obtained as a function of the electron energy. The electron energy scale was calibrated with the s-wave DEA reaction of $\mathrm{CCl}_{4}$ which leads to resonant formation of $\mathrm{Cl}^{-}$at about $0 \mathrm{eV}$ [26]. The FWHM of this resonance was also used to determine the energy resolution of the electron beam.

\section{Computational Details}

Thermochemical reaction thresholds were calculated employing the G4(MP2) method [27], which is the most recent of the Gx extrapolation schemes. This approach yields an average deviation of about $0.05 \mathrm{eV}$ from experiment for the 454 energies compiled in the G3/05 test set [27]. As trialanine and its fragments are organic molecules with features (such as $\mathrm{C}-\mathrm{C}, \mathrm{C}-\mathrm{N}$ bonds, etc.) well described in that test set, the G4(MP2) method is estimated to be accurate within at least $0.1-0.15 \mathrm{eV}$ for our cases. In particular, the ground state energies of reactants, $\mathrm{E}(\mathrm{R})$, and products, $\mathrm{E}(\mathrm{P})$, were calculated and subsequently the reaction threshold, $\mathrm{E}(\mathrm{P} \rightarrow \mathrm{R})$, was calculated as $\mathrm{E}(\mathrm{P} \rightarrow \mathrm{R})=\mathrm{E}(\mathrm{R})-\mathrm{E}(\mathrm{P})$. The temperature in these calculations was set to room temperature as well as to $460 \mathrm{~K}$ (slightly higher than the temperature in the experiment) in order to explore any effect of the elevated temperature on the reaction energetics. We found that the effect on the resulting reaction thresholds is of the order of a few tens of $\mathrm{meV}$ and is thus rather negligible for the cases studied here. For that reason, we report only the energies obtained using the elevated temperature of $460 \mathrm{~K}$. The results are summarized in Table 1. All calculations have been performed using the Gaussian 09 suite of programs [28].

As initial geometries of the parent molecule two different conformers have been used. These are depicted in Fig. 1. Conformer I exhibits a H-O-C-C-N-C-O ring structure (Fig. 1a) and is by about $0.05 \mathrm{eV}$ more stable than the 'linear' conformer II shown in Fig. 1b. Given a temperature of $460 \mathrm{~K}$ and assuming a Boltzmann distribution for the amount of molecules resembling these configurations, we find that the ratio of populations according to the conformers (a) and (b) shown in Fig. 1 is about 1/3. Hence, we expect that under the experimental conditions both conformers are present in the gas phase which shall be reflected in the recorded ion efficiency curves. This is taken into account in the following discussion. 


\section{Results and Discussion}

Electron attachment to trialanine was studied in the electron energy range from about zero up to $4 \mathrm{eV}$. Within the detection limit of the apparatus no parent anion was observable on mass spectrometric time scales analogously to the electron attachment studies of dialanine and alanine. The heaviest fragment anion observed in the present DEA experiment is assigned to the dehydrogenated parent anion, $(\mathrm{M}-\mathrm{H})^{-}$, formed in the DEA reaction

$$
\mathrm{C}_{9} \mathrm{H}_{17} \mathrm{~N}_{3} \mathrm{O}_{4}+\mathrm{e}^{-} \rightarrow \mathrm{C}_{9} \mathrm{H}_{16} \mathrm{~N}_{3} \mathrm{O}_{4}^{-}+\mathrm{H}
$$

The corresponding ion yield shows a low-energy feature with a threshold at $\sim 0.6 \mathrm{eV}$ which extends up to $3 \mathrm{eV}$. The ion yield is shown in Fig. 2a and consists of a sharp peak located at about $0.77 \mathrm{eV}$ superposed on a broad feature with a maximum at about $1.15 \mathrm{eV}$. In previous studies with single amino acids (e.g., [6,7,9,24,31]) a pronounced site selectivity of the $\mathrm{H}$-loss was observed, where low energy features $(<3 \mathrm{eV})$ have been ascribed to exclusive loss of the hydrogen from the carboxyl group. This was suggested for amino acids using three different approaches, (i) thermochemical calculations [29] which indicated that the threshold for $(\mathrm{M}-\mathrm{H})^{-}$formation with H-removal from the carboxyl group is the lowest one amongst all sites, (ii) experiments with partially labelled molecules [6,7,9] and (iii) scattering calculations which are based on the occupation of the repulsive $\sigma^{*}$-orbital of the carboxyl group by the excess charge $[9,24]$.

The $(\mathrm{M}-\mathrm{H})^{-}$thresholds from the present thermochemical calculations are presented in Section 3 and summarized in Table 1. Thresholds for H-loss from carboxyl, amino and the two amide groups have been calculated for the two different conformers shown in Fig. 1; the thresholds accompanied by $\mathrm{H}$-loss from carbon sites were not determined since it can be expected that those are higher. The values for both conformers indicate that the H-loss from carboxyl group is energetically most favourable (threshold value of $0.40 \mathrm{eV}$ for conformer I and $0.36 \mathrm{eV}$ for conformer II, respectively). However, for the two amide groups the thresholds are considerably different for the two conformers. For conformer II threshold values of 1.02 and $1.13 \mathrm{eV}$ are derived, while for conformer I the values are considerably lower $(0.50 \mathrm{eV}$ and $0.72 \mathrm{eV}$, respectively). Since both conformers are expected to be present in the molecular beam at the temperatures used, we cannot exclude that $\mathrm{H}$-loss from amide groups contribute to H-loss from the carboxyl group. The present data do not allow an 
unambiguous assignment but we may refer to a MS/MS study combined with MD-simulations for the dipeptide dialanine where the $(\mathrm{M}-\mathrm{H})^{-}$ion yield was assigned to abstraction of a hydrogen atom from the carboxyl group and amide group, contributing with two distinct resonances at 0.81 and $1.17 \mathrm{eV}$, respectively.

The $(\mathrm{M}-\mathrm{H})^{-}$yield in DEA to alanine showed only one asymmetric peak (with a steep onset at the low energy side) with a maximum located at $1.25 \mathrm{eV}$ [29]. The thermochemical threshold in the case of the single amino acid was determined to be $1.2 \mathrm{eV}$, i.e. substantially higher compared to the tripeptide. Thus the ion yield shape on the low energy side seems mostly determined by the threshold value which will lead to the cut-off of the resonant yield like in the case of alanine causing the steep onset. In a recent DEA study with isomers of aminobutanoic acid the same tendency has been observed [9]. The threshold value (slightly different for the three studied isomers) strongly influenced the ion yield shape for H-loss from the carboxyl group. However, R-matrix scattering calculations for the isomers of aminobutanoic acid also showed that the effective ion yield is strongly dependent on the short range electron-molecule interaction in addition to the long range potentials (polarization and dipolar interaction) which are usually associated with threshold structures [9].

The second heaviest fragment anion observed in the present DEA experiments is observed at mass $158 \mathrm{u}$ and ascribed to $\mathrm{C}_{6} \mathrm{H}_{12} \mathrm{~N}_{3} \mathrm{O}_{2}^{-}$formed in the reaction

$$
\mathrm{C}_{9} \mathrm{H}_{17} \mathrm{~N}_{3} \mathrm{O}_{4}+\mathrm{e}^{-} \rightarrow \mathrm{C}_{6} \mathrm{H}_{12} \mathrm{~N}_{3} \mathrm{O}_{2}^{-}+\mathrm{C}_{3} \mathrm{H}_{5} \mathrm{O}_{2}
$$

The corresponding reaction scheme for the formation of this fragment anion upon DEA is shown in Fig. 3a and the ion yield is shown in Fig. 2b. The anion is formed in a single symmetric resonance at $1.91 \mathrm{eV}$. The peak onset as well the maximum are above the calculated thermodynamic threshold of 0.44 for conformer I ( $0.42 \mathrm{eV}$ for conformer II) and thus we ascribe the resonance yield to the simple bond cleavage reaction shown in Reaction (2). Using the well-known nomenclature for peptide fragmentation by Roepstorff and Fohlman [30] the fragment anion formed is the $\mathrm{c}_{2}$ anion formed by the cleavage of the $\mathrm{N}-\mathrm{C}_{\alpha}$ bond. Concerning the molecular orbitals involved in the DEA process we refer to a previous computational study on the orbitals energies of dialanine which supported the previous experimental observation of the c anion at energies below $2.5 \mathrm{eV}$. Sobczyk et al. [31] suggested an indirect mechanism, where the incoming electron is first captured into the $\pi^{*}$ orbital of the central $\mathrm{C}=\mathrm{O}$ carbonyl group before electronic coupling with the repulsive $\sigma^{*} \mathrm{~N}-$ $\mathrm{C}_{\alpha}$ orbital occurs which leads to the dissociation of the molecule. The same molecular groups 
involved are also present for trialanine and thus we suggest the same mechanism in the $\mathrm{c}_{2}$ anion formation like earlier for dialanine [18]. By this mechanism the formation of the $c_{2}$ anion in the low electron energy range is energetically possible.

Another fragment anion formed by cleavage of the trialanine chain which can be observed in the present experiment is $\mathrm{C}_{6} \mathrm{H}_{9} \mathrm{NO}_{3}{ }^{-}$with mass $143 \mathrm{u}$. One possible reaction scheme is

$$
\mathrm{C}_{9} \mathrm{H}_{17} \mathrm{~N}_{3} \mathrm{O}_{4}+\mathrm{e}^{-} \rightarrow \mathrm{C}_{6} \mathrm{H}_{9} \mathrm{NO}_{3}{ }^{-}+\mathrm{C}_{3} \mathrm{H}_{7} \mathrm{~N}_{2} \mathrm{O}+\mathrm{H}
$$

Using the notation for peptide cleavage reaction (3) is hence accompanied by formation of the $z_{2}-1$ anion. The ion yield is shown in Fig. $2 c$ and is characterized by two features, (i) a sharp zero eV resonance which is (ii) followed a comparable broad resonance located at about $1.20 \mathrm{eV}$. We calculated the thermochemical thresholds for reaction (3) assuming additional Hloss from the $\mathrm{z}$ anion from either the carboxyl group or amide group and obtained for conformer II threshold values of $4.45 \mathrm{eV}$ or $5.37 \mathrm{eV}$, respectively. For conformer I the threshold are also found to be $>4.5 \mathrm{eV}$. The experimentally observed resonances are few eV lower than the calculated thresholds and thus the anion yield cannot form via reaction (3). However, the thermochemical calculations indicate that $\mathrm{C}_{6} \mathrm{H}_{9} \mathrm{NO}_{3}{ }^{-}$may form in a rearrangement reaction as shown in Fig. 3b, i.e. via the reaction

$$
\mathrm{C}_{9} \mathrm{H}_{17} \mathrm{~N}_{3} \mathrm{O}_{4}+\mathrm{e}^{-} \rightarrow \mathrm{C}_{6} \mathrm{H}_{9} \mathrm{NO}_{3}{ }^{-}+\mathrm{C}_{3} \mathrm{H}_{8} \mathrm{~N}_{2} \mathrm{O}
$$

In this case the second $\mathrm{N}-\mathrm{C}$ bond is broken in the DEA reaction after the incoming electron is first captured into the $\pi^{*}$-orbital of the $\mathrm{C}=\mathrm{O}$ carbonyl group close to the amino group, i.e. a negatively charged $c_{1}$ and a neutral $z_{2}$ fragment is formed. However, in contrast to the $c_{2}$ anion, where the excess charge remains at the amide group, a proton transfer from the neutral $\mathrm{z}_{2}$ counterpart may occur. The initially formed $\mathrm{c}_{1}$ anion becomes neutralized in this reaction step, and the $z_{2}-1$ anion is hence formed as proposed in reaction (4). Such a proton transfer reaction was previously suggested to be present in DEA to polypeptides [18]. We further investigated the thermochemistry of the DEA reaction (4) by assuming different protons to be transferred from the $z_{2}$ fragment. While for proton transfer from the amide group the threshold for reaction (4) is $0.59 \mathrm{eV}$, the threshold is considerable lower for proton transfer from the carboxyl group. In the latter case the DEA reaction becomes exothermic by $0.33 \mathrm{eV}$. The values mentioned refer to conformer II. For conformer I both reactions become 
exothermic (see Table 1). Thus, we ascribe the zero-eV-threshold peak to the formation of $\mathrm{z}_{2}$ 1 anion by a proton transfer from the carboxyl group while the broad resonance is formed by proton transfer from the amide group of the $\mathrm{z}_{2}$ fragment.

Within the detection limit of the apparatus we were able to observe a fourth fragment anion, which was found at mass $88 \mathrm{u}$ ( $\mathrm{y}_{1}$ anion). Assuming DEA, the ion yield may be ascribed to the following reaction where a peptide bond is broken,

$$
\mathrm{C}_{9} \mathrm{H}_{17} \mathrm{~N}_{3} \mathrm{O}_{4}+\mathrm{e}^{-} \rightarrow \mathrm{C}_{3} \mathrm{H}_{6} \mathrm{NO}_{2}^{-}+\mathrm{C}_{6} \mathrm{H}_{11} \mathrm{~N}_{2} \mathrm{O}_{2}
$$

The corresponding ion yield on the latter mass is shown in Fig. 2d. In the low electron energy regime the anion is formed in a single resonance located at about $1.2 \mathrm{eV}$. Previously, it was suggested in [18] that a peak at $88 \mathrm{u}$ in the low-energy negative ion mass spectrum of trialanine may be assigned to the single amino acid alanine. Here the ion yield shape is characterized by an asymmetric peak shape with a steep onset on the low energy tail which is indeed very reminiscent of the $(\mathrm{M}-\mathrm{H})^{-}$ion yield of the single amino acid alanine. In addition, the calculated thermochemical threshold for reaction (5) is $2.76 \mathrm{eV}$. Hence we cannot ascribe the observed ion yield to reaction (5). Instead we assume the previously tentative assignment that this anion yield is caused by DEA to alanine which is present as impurity in the sample or is formed by thermal decomposition of the alanine sample.

The previous negative ion mass spectrum mentioned has been determined by Deinzer and co-workers [18] at the electron energy of $1.5 \pm 0.5 \mathrm{eV}$. They utilized a double focusing mass spectrometer and observed the most intense signals in their mass spectrum for $(\mathrm{M}-\mathrm{H})^{-}, \mathrm{z}_{2}-1$ anion, $\mathrm{c}_{2}$ anion and $\left(\mathrm{M}-\mathrm{H}_{2}\right)^{-}$(listed in the order of decreasing intensity). In the present experiment we were not able to detect $\left(\mathrm{M}-\mathrm{H}_{2}\right)^{-}$due to the low cross section of its formation combined with the reduced transmission of the quadrupole analyzer for heavier anions. Otherwise the present results are in good agreement with the previous ones concerning the anions detected. However, it should be noted that previously the formation of $(\mathrm{M}-\mathrm{H})^{-}$in polypeptides has also been associated with the carboxylate anions structure involving dipole bound states [32]. Though there is no direct proof by the present study that H-loss from another site may contribute to the measured ion yield, it should be mentioned that H-loss from the amide group at energies $<3 \mathrm{eV}$ is also possible from a thermodynamic point of view.

\section{Conclusion}


In the present DEA study on the tripeptide trialanine we investigated resonant formation of fragment anions in the electron energy range from about $0 \mathrm{eV}$ to $4 \mathrm{eV}$ and determined the ion yields as a function of the electron energy. Four fragment anions $\left((\mathrm{M}-\mathrm{H})^{-}, \mathrm{c}_{2}, \mathrm{z}_{2}-1\right.$ and $\mathrm{y}_{1}$ anions) have been detected within the detection limit of the apparatus. The thermochemistry of these anions has been investigated using quantum chemical calculations. The thresholds have turned out to be strongly dependent on the structure of the tripeptide which was derived when including internal hydrogen bonding of the carboxyl hydrogen with the oxygen of the neighboring amide group. The present results show that trialanine is susceptible to low energy electrons $<3 \mathrm{eV}$ like it was found for the subunit alanine and for the dipeptide dialanine. However, we show that in contrast to the smaller species also zero eV electrons are able to break the chain of the peptide. This is energetically only possible via a more complex reaction including a subsequent proton transfer from the neutral $z_{2}$ fragment after the initial DEA process. The negative mass spectra at $1.5 \mathrm{eV}$ for alanine polypeptides (up to the hexapeptide) measured by Deinzer and co-workers [18] indicated that the z-1 anions become the dominant anions in the low energy fragmentation patterns with increasing peptide size. Hence, it can be expected in DEA to polypeptides that subsequent proton transfer reactions will determine the final localization of excess charge after initial DEA.

\section{Acknowledgments}

This work has been supported by the Fonds zur Förderung der wissenschaftlichen Forschung (FWF projects, P22665 and I200-N29) and by the Austrian Ministry of Science BMWF as part of the UniInfrastrukturprogramm of the Research Platform Scientific Computing at the University of Innsbruck. S.E.H. is funded by the FWF DK+ on Computational Interdisciplinary Modelling, W 1227-N16. We thank Dr. Violaine Vizcaino for detailed reading of our manuscript. 


\section{References}

[1] E. Surdutovich, A.V. Yakubovich, A.V. Solov'yov, Eur. Phys. J. D 60, 101 (2010)

[2] M. Mucke, M. Braune, S. Barth, M. Förstel, T. Lischke, V. Ulrich, T. Arion, U. Becker, A. Bradshaw, U. Hergenhahn, Nature Physics 6, 143 (2010)

[3] S.M. Pimblott, J.A., Laverne, Radiation Physics and Chemistry 76, 1244 (2007)

[4] B. Boudaïffa, P. Cloutier, D. Hunting, M.A. Huels, L. Sanche, Science 287, 1658 (2000)

[5] A. Keller, J. Kopyra, K.V. Gothelf, I. Bald, New J. Phys. 15, 083045 (2013)

[6] Y.V. Vasil'ev, B.J. Figard, V.G. Voinov, D.F. Barofsky, M. L. Deinzer, J. Am. Chem. Soc. 128, 5506 (2006)

[7] H.D. Flosadottir, S. Denifl, F. Zappa, N. Wendt, A. Mauracher, A. Bacher, H. Jonsson, T.D. Märk, P. Scheier and O. Ingolfsson, Angew. Chem. Int. Ed. 46, 8057 (2007)

[8] P. Papp, J. Urban, S. Matejcik, M. Stano and O. Ingólfsson, J. Chem. Phys. 125, 204301 (2006)

[9] V. Vizcaino, B. Puschnigg, S.E. Huber, M. Probst, I.I. Fabrikant, G.A. Gallup, E. Illenberger, P. Scheier, S. Denifl, New J. Phys. 14, 043017 (2012)

[10] J. Kopyra, Chem. Phys. Lett. 533, 87 (2012)

[11] J. Kopyra, I. Szamrej, H. Abdoul-Carime, B. Farizon, M. Farizon, PhysChemChemPhys 14, 8000 (2012)

[12] V. Vizcaino, P. Bartl, D. Gschliesser, S.E. Huber, M. Probst, T.D. Märk, P. Scheier, S. Denifl, ChemPhysChem 12, 1272 (2011)

[13] P.V. Shchukin, M.V. Muftakhov, J. Morre, M.L. Deinzer, Y.V. Vasil'ev, J. Chem. Phys 132, 234306 (2010)

[14] J. Kocisek, P. Papp, P. Mach, Y.V. Vasil'ev, M.L. Deinzer, S. Matejcik, J. Phys. Chem. 114, $1677(2010)$

[15] E. Alizadeh, D. Gschliesser, P. Bartl, M. Hager, A. Edtbauer, V. Vizcaino, A. Mauracher, M. Probst, T. D. Märk, S. Ptasińska, N.J. Mason, S. Denifl, P. Scheier, J. Chem. Phys. 134, 054305 (2011)

[16] D. Gschliesser, V. Vizcaino, M. Probst, P. Scheier, S. Denifl, Chem. Eur. J. 18, $4613(2012)$

[17] M.V. Muftakhov, P.V. Shchukin, PhysChemChemPhys. 13, 4600 (2011) 
[18] Y.V. Vasil'ev, B.J. Figard, J. Morré, M.L. Deinzer, J. Chem. Phys. 131, $044317(2009)$

[19] B. Puschnigg, S.E. Huber, M. Probst, K. Tanzer, V. Vizcaino, F. Ferreira da

Silva, P. Scheier, P. Limao-Vieira, S. Denifl, PhysChemChemPhys 15, 3834 (2013)

[20] J. Kopyra, C. König-Lehmann, E. Illenberger, Chem. Phys. Lett. 578, 54 (2013)

[21] J. Kopyra, C. König-Lehmann, E. Illenberger, Chem. Phys. Lett. 550, 47 (2012)

[22] P.V. Shchukin, M.V. Muftakhov, A.V. Pogulay, Rapid. Comm. Mass Spect. 26, $828(2012)$

[23] H.J. Yoo, N. Wang, S. Zhuang, H. Song, K. Hakansson, J. Am. Chem. Soc. 133, $16790(2011)$

[24] G.A. Gallup, P.D. Burrow, I.I. Fabrikant, Phys. Rev. A 79, 042701 (2009)

[25] S. Denifl, S. Ptasińska, B. Sonnweber, P. Scheier, D. Liu, F. Hagelberg, J.

Mack, L. T. Scott and T. D. Märk, J. Chem. Phys. 123, 104308 (2005)

[26] H. Hotop, M.-W. Ruf, M. Allan, I.I. Fabrikant, Adv. At. Mol. Phys. 49, 85 (2003)

[27] L.A. Curtiss, P.C. Redfern and K. Raghavachari, J. Chem. Phys. 127, 124105 (2007)

[28] M.J. Frisch, G.W. Trucks, H.B. Schlegel, G.E. Scuseria, M.A. Robb, J.R. Cheeseman, G. Scalmani, V. Barone, B. Mennucci, G. A. Petersson, H. Nakatsuji, M. Caricato, X. Li, H.P. Hratchian, A.F. Izmaylov, J. Bloino, G. Zheng, J.L. Sonnenberg, M. Hada, M. Ehara, K. Toyota, R. Fukuda, J. Hasegawa, M. Ishida, T. Nakajima, Y. Honda, O. Kitao, H. Nakai, T. Vreven, J.A. Montgomery, Jr., J.E. Peralta, F. Ogliaro, M. Bearpark, J.J. Heyd, E. Brothers, K.N. Kudin, V.N. Staroverov, R. Kobayashi, J. Normand, K. Raghavachari, A. Rendell, J.C. Burant, S.S. Iyengar, J. Tomasi, M. Cossi, N. Rega, J.M. Millam, M. Klene, J.E. Knox, J.B. Cross, V. Bakken, C. Adamo, J. Jaramillo, R. Gomperts, R.E. Stratmann, O. Yazyev, A.J. Austin, R. Cammi, C. Pomelli, J.W. Ochterski, R.L. Martin, K. Morokuma, V.G. Zakrzewski, G.A. Voth, P. Salvador, J.J. Dannenberg, S. Dapprich, A.D. Daniels, O. Farkas, J.B. Foresman, J.V. Ortiz, J. Cioslowski and D.J. Fox, Gaussian 09 Revision A.1, Gaussian, Inc., Wallingford, CT, 2009.

[29] S. Ptasinska, S. Denifl, P. Candori, S. Matejcik, P. Scheier, T. D. Märk, Chem. Phys. Lett. 403, 107(2005) 
[30] P. Roepstorff, J. Fohlman Biomed. Mass Spectrom. 11, 601 (1984)

[31] M. Sobczyk, I. Anusiewicz, J. Berdys-Kochanska, A. Sawicka, P. Skurski and J. Simons, J. Phys. Chem. A 109, 250 (2005)

[32] T. Sommerfeld, PhysChemChemPhys 4, 2511 (2002) 
Table 1. Thermochemical threshold energies of possible fragmentation channels in DEA to trialanine. Conformer I and II correspond to the structures shown in Fig. 1a and $1 \mathrm{~b}$, respectively. All values correspond to a temperature of $460 \mathrm{~K}$ except those indicated by an asterisk which were determined for ambient temperature.

\begin{tabular}{|l|c|c|}
\hline Reaction $\mathrm{e}^{-}+\mathrm{M} \rightarrow \ldots$ & \multicolumn{2}{|c|}{ Threshold energy (in eV) } \\
\cline { 2 - 3 } & Conformer I & Conformer II \\
\hline$(\mathrm{M}-\mathrm{H})^{-}+\mathrm{H}[\mathrm{H}$ from carboxyl group] & 0.40 & 0.36 \\
\hline$(\mathrm{M}-\mathrm{H})^{-}+\mathrm{H}[\mathrm{H}$ from amide group 1 (close to carboxyl)] & 0.50 & 1.02 \\
\hline$(\mathrm{M}-\mathrm{H})^{-}+\mathrm{H}[\mathrm{H}$ from amide group 2 (close to amino)] & 0.72 & $1.13^{*}$ \\
\hline$(\mathrm{M}-\mathrm{H})^{-}+\mathrm{H}[\mathrm{H}$ from amino group] & 2.24 & $2.65^{*}$ \\
\hline & & \\
\hline $\mathrm{C}_{6} \mathrm{H}_{12} \mathrm{~N}_{3} \mathrm{O}_{2}^{-}+\mathrm{C}_{3} \mathrm{H}_{5} \mathrm{O}_{2}$ & 0.44 & 0.40 \\
\hline & & \\
\hline $\mathrm{C}_{6} \mathrm{H}_{9} \mathrm{NO}_{3}^{-}+\mathrm{C}_{3} \mathrm{H}_{7} \mathrm{~N}_{2} \mathrm{O}+\mathrm{H}[\mathrm{H}$ from carboxyl group] & 4.49 & 4.45 \\
\hline $\mathrm{C}_{6} \mathrm{H}_{9} \mathrm{NO}_{3}^{-}+\mathrm{C}_{3} \mathrm{H}_{7} \mathrm{~N}_{2} \mathrm{O}+\mathrm{H}[\mathrm{H}$ from amide group 1] & 4.66 & 5.37 \\
\hline $\mathrm{C}_{6} \mathrm{H}_{9} \mathrm{NO}_{3}{ }^{-}+\mathrm{C}_{3} \mathrm{H}_{8} \mathrm{~N}_{2} \mathrm{O}\left[\mathrm{H}^{+}\right.$transfer from carboxyl group] & -0.29 & -0.33 \\
\hline $\mathrm{C}_{6} \mathrm{H}_{9} \mathrm{NO}_{3}^{-}+\mathrm{C}_{3} \mathrm{H}_{8} \mathrm{~N}_{2} \mathrm{O}\left[\mathrm{H}^{+}\right.$transfer from amide group 1] & -0.12 & 0.59 \\
\hline & & \\
\hline $\mathrm{C}_{3} \mathrm{H}_{6} \mathrm{NO}_{2}{ }^{-}+\mathrm{C}_{6} \mathrm{H}_{11} \mathrm{~N}_{2} \mathrm{O}_{2}$ & 2.76 & 2.71 \\
\hline
\end{tabular}


(a)

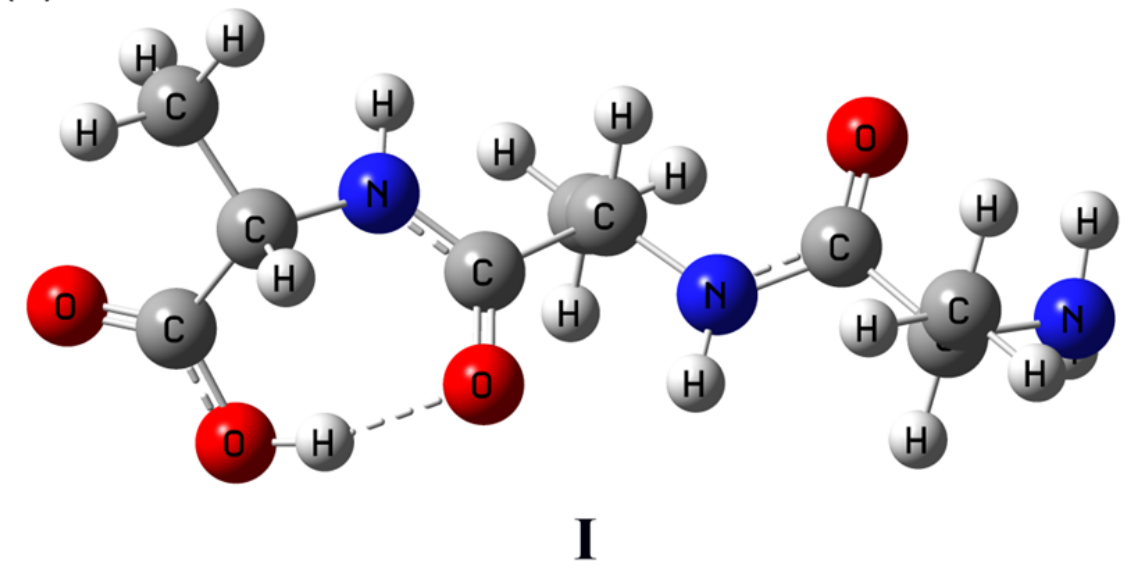

(b)

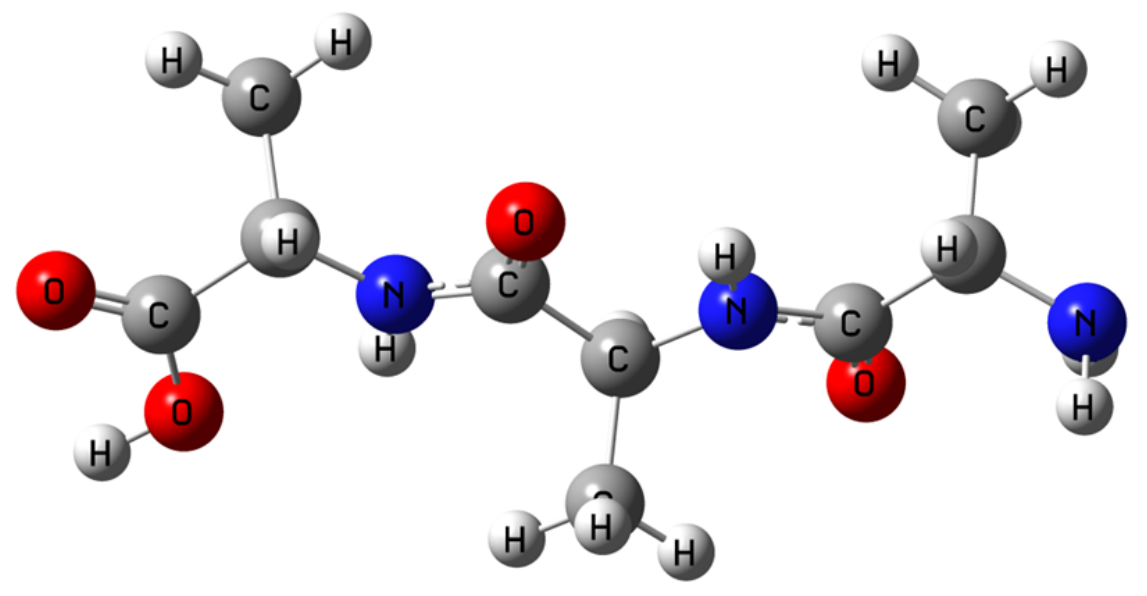

II

Figure 1. Structure of two possible conformers of trialanine. Conformer I (a) is about $0.05 \mathrm{eV}$ more stable than isomer II (b) (see text). The structures were obtained at the B3LYP/6$31 \mathrm{G}(2 \mathrm{df}, \mathrm{p})$ level of theory which is used for the geometry optimization in the G4(MP2) extrapolation scheme. 

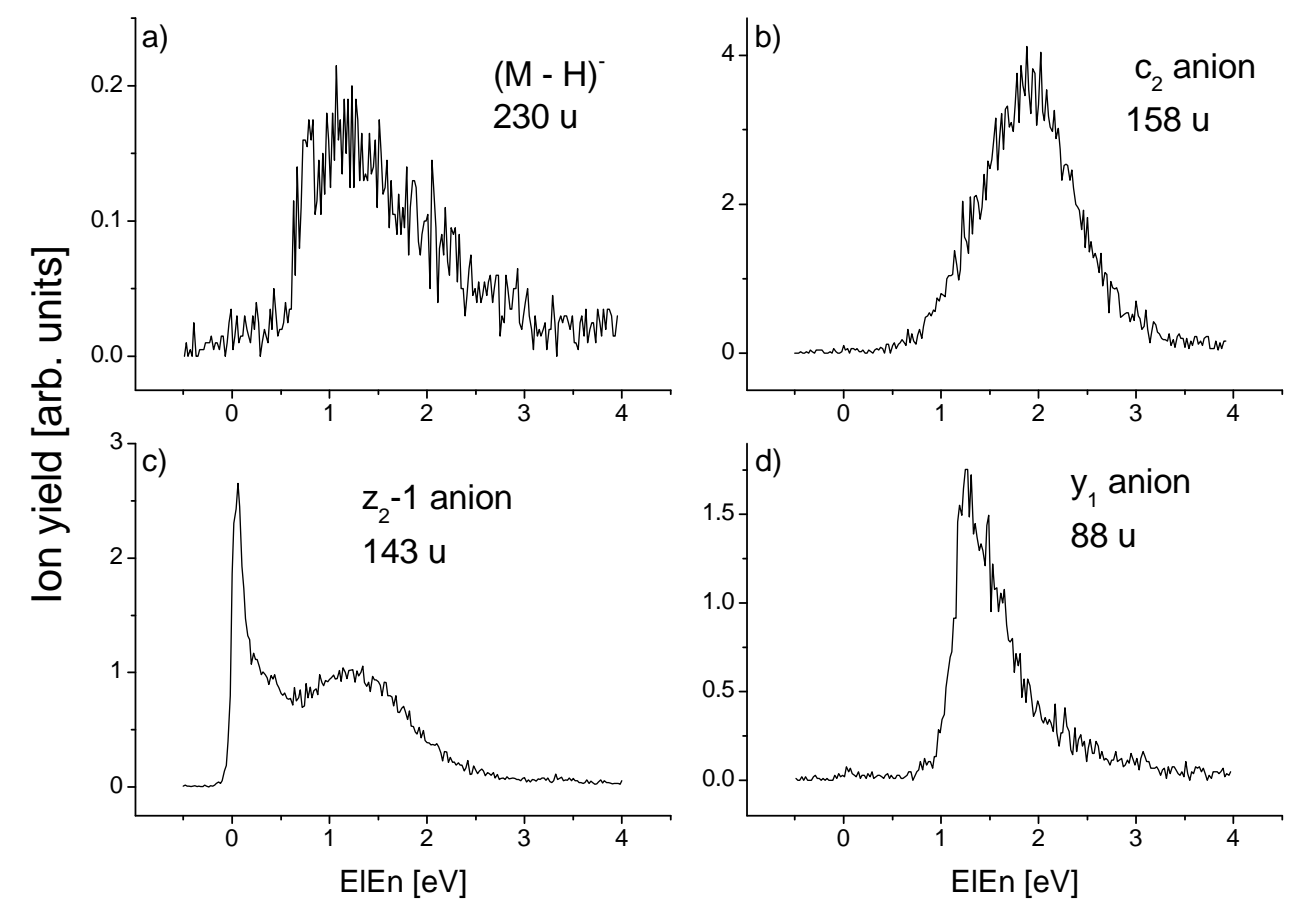

Figure 2. Ion yields of fragment anions observed in the present DEA study of trialalanine (see text). 
a)

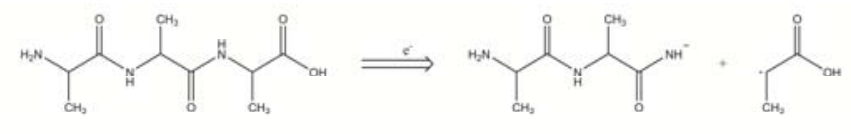

b)

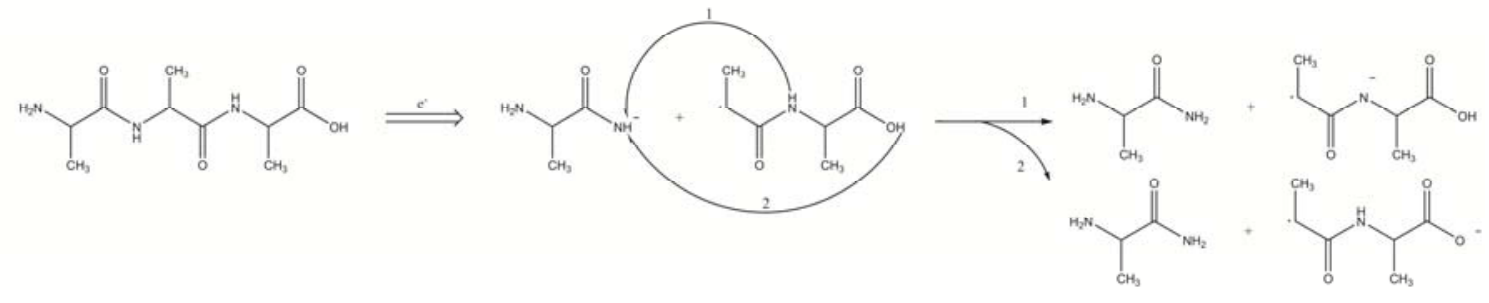

Figure 3. Possible reaction schemes for the fragment anions observed in DEA to trialanine. Using common nomenclature for peptide fragmentation the negatively charged fragment formed in a) is the $c_{2}$ fragment. In $b$ ) the negatively charged $z_{2}-1$ and neutral $c_{1}$ fragments are formed as final reaction products (see text). 